\title{
DE LA JURISPRUDENCIA A LA LEGISLACIÓN
}

\section{El desinterés del jurista por el proceso legislativo}

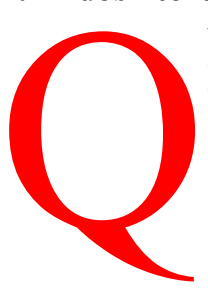
uienes hemos tenido la suerte -y la seguimos teniendo- de trabajar con Elías Díaz sabemos que una de sus preocupaciones más reiteradas es la de cómo conseguir una concepción totalizadora, y crítica del fenómeno jurídico. Fue esta la idea clave de su libro Filosofía y Sociología del Derecho, sobre la que desde 1971 no ha dejado de insistir ${ }^{1}$.

Una concepción totalizadora del fenómeno jurídico no sólo supone -como nos ha enseñado Elías Díaz- partir del respeto metodológico a la norma para, acto seguido, examinarla críticamente con el concurso de la sociología y la filosofía del derecho. Una concepción totalizadora del derecho debe examinar, además, con mayor atención lo que hay antes de la norma; esto es, el proceso de su creación.

La formación tradicional del jurista ha desdeñado, hasta cierto punto, el estudio del proceso normativo: su punto de partida ha sido siempre la norma promulgada. Y así, cuando ha tenido que estudiar la gestación de la norma, desde lo que Hart denominaría «punto de vista interno», no ha ofrecido una visión unitaria del proceso -diseccionadas sus partes entre el derecho constitucional y el derecho administrativo- ni se ha fijado en aspectos capitales de la génesis de la norma como qué es lo que determina el ejercicio de la iniciativa legislativa o la potestad reglamentaria, cómo se han de analizar las causas del problema a resolver, cuáles son los objetivos perseguidos, cómo conseguir que la norma alcance la racionalidad lingüística,

${ }^{1}$ Elías Díaz, Filosofía y Sociología del Derecho, Taurus, Madrid, 1971. En Legitimidad crítica y pluralismo ideológico, publicado en los Anales de la Cátedra Francisco Suárez, no . 15, 1975, y en Legalidad y legitimidad en el socialismo democrático (Civitas, Madrid, 1977) reitera lo que es la idea directriz de esta concepción. 
lógico-formal, pragmática, teleológica y ética a que se refiere, entre otros, Manuel Atienza². Los planes de estudio han abandonado estas cuestiones a otras disciplinas -o a ninguna- pese a ser cuestiones que afectan a la calidad de las normas, a su efectividad, a su eficacia y a su eficiencia. Y, tal vez por ello, en algún sentido, a su justicia.

Pero tampoco el «punto de vista externo» del derecho que supone la sociología se ha ocupado suficientemente de la producción normativa. Cuando el profesor Renato Treves ${ }^{3}$ analiza los campos en que se centra la investigación empírica de la sociología se pone de relieve cómo el de la producción normativa no es precisamente el más cultivado. Aunque tal vez sea un tanto exagerado afirmar que la sociología de la legislación puede caminar por senderos prácticamente vírgenes ${ }^{4}$, es cierto que parece preferir las investigaciones sobre aplicación y no aplicación de normas, comportamiento de los operadores jurídicos (jueces y abogados) o comparaciones entre sistemas. Las investigaciones directamente aplicables a los problemas prácticos a los que se enfrenta un legislador son realmente excepcionales.

Por lo que se refiere a la teoría general del derecho, sus cultivadores han tenido que recorrer otros dominios como el de la teoría de la norma y la teoría del ordenamiento. Ha cobrado, igualmente, una pujanza excepcional el estudio de los problemas de la argumentación y aplicación del derecho. Pero, preocupada la teoría del derecho por lo que hacen los jueces, no se ha ocupado suficientemente de lo que hacen los legisladores.

Tan sólo la filosofía del derecho ha tratado siempre de mantener vivo el espíritu crítico ante las normas vigentes y hacer de la justicia el paradigma de la legislación. Pero no es ciertamente suficiente porque, como señala Albert Calsamiglia ${ }^{5}$ la moral no puede ser el único criterio para legislar.

Y así, juristas, sociólogos y filósofos del derecho han dejado a un lado el estudio del momento de la producción normativa, de la relación -como dice Gregorio Peces-Barba ${ }^{6}$ del poder y del derecho, de la concepción y nacimiento de la norma, el momento «impuro», pero capital, donde la política se convierte en derecho.

\footnotetext{
${ }^{2}$ Manuel Atienza, Lenguaje, lógica jurídica y teoría de las normas, en Técnica normativa de las Comunidades Autónomas, Comunidad de Madrid, 1991.

${ }^{3}$ Renato Treves, La sociología del derecho. -Orígenes, investigaciones y problemas, Ariel Derecho, 1988, págs. 166 y ss.

${ }^{4}$ Pierre Gubentif, «A produçao do direito. Critica de um conceito na frontera entre sociologia do direito e ciencia de legislaçao» en la revista Legislaçao nº. 7, abril-junio 1993.

${ }^{5}$ Albert Calsamiglia, ¿Debe ser la moral el único criterio para legislar? Doxa, Cuadernos de Filosofía del Derecho, $\mathrm{n}^{\circ}$ 13, 1993.

${ }^{6}$ Gregorio Peces-Barba, Introducción a la filosofía del derecho, Editorial Debate, $2^{\mathrm{a}}$ reimpresión 1988, págs. 29 y ss.
} 
No siempre fue así.

El interés teórico por la legislación en los países anglosajones es ya muy antiguo y data, cuando menos, del pasado siglo.

El peculiar procedimiento de redacción de las normas en el sistema anglosajón ha dado lugar históricamente a una institucionalizacion muy consolidada del procedimiento: desde 1869 el Office of Parliamentary Counsel, órgano al que se encomienda la redacción de los proyectos de ley, ha desarrollado y consolidado unas técnicas de redacción normativa que se han extendido por todos los países de cultura anglosajona.

Este interés práctico por las técnicas de legislación ha estado acompañado por una no menos significativa preoupación de la doctrina por estos temas. Baste referirnos a las obras de Bentham, Dicey, Austin, Llewellyn o R. Pound. Es Austin quien en The Province of Jurisprudence determined and the uses of the study of Jurisprudence ${ }^{7}$ diferencia la Ciencia de la Jurisprudencia (que se ocupa de las leyes positivas sin considerar su bondad o maldad) de aquella rama de la Ciencia de la Ética que denomina Ciencia de la Legislación y que trata de determinar los principios sobre los que deben elaborarse las normas si quieren merecer la aprobación; esto es, cómo deberían ser las leyes o cómo serían si fueran buenas leyes, o cómo serían si se adecuaran a una determinada medida. A este tipo de estudios Austin los denominaba Ciencia de la Legislación o simplemente Legislación.

Pero, tambien en el Continente la doctrina se ocupó en otro tiempo de la Legislación. Las obras de Monstesquieu, Beccaría, Rousseau, Ihering... etc., o, ya en nuestro siglo -en un tono menor-, Geny, Ripert, Capitan o Carbonier son buena prueba de que el interés por la legislación ha existido siempre, si bien ha adolecido de una cierta desconexión y discontinuidad.

¿Cuál es, entonces, la razón de que haya en la actualidad tantos «intérpretes» y tan pocos «proyectistas» de normas? ¿Porqué se ha ido «desvaneciendo» aquella ciencia de la legislación?

Coincido con la apreciación de Sabino Cassese $^{8}$ en el sentido de que la concepción hoy en día dominante según la cual la ciencia del derecho comienza a partir de la ley, y no antes, trae causa del principio de la soberanía del Parlamento (cultura anglosajona) y de la hegemonía del positivismo jurídico (tanto en el continente como en Inglaterra).

Como es sabido fue un suizo admirador del sistema británico, De Lolme, quien trató de sintetizar la esencia del modelo anglosajón

${ }^{7}$ Weidenfeld and Nicolson, 4a impresión, London, 1971.

${ }^{8}$ «Introduzione allo studio della normazione», Riv. Trim. Dir. pubbl. 2/1992, págs. 307 y ss. 
con la afirmación de que el Parlamento puede hacerlo todo, excepto convertir a un hombre en una mujer. Por su parte Albert Venn Dicey9 ${ }^{9}$ desarrolló en 1885 la teoría de la soberanía legislativa del Parlamento. Pese al «error» de dicha teoría («olvidaba» que en el derecho inglés la norma era entonces de formación jurisprudencial fundamentalmente y que, por otra parte, en la estructura inglesa el órgano clave era, y sigue siendo, el Gabinete) la idea de la omnipotencia del Parlamento se convirtió en un auténtico mito jurídico. Mito que, si, entre otras ventajas, sirvió para modernizar el sistema y anclar al juez a la ley, esto es a la soberanía popular, hizo del jurista un exégeta de la misma: las técnicas de redacción detallada de las normas en la cultura anglosajona tienen como objetivo afirmar continuamente la primacía de la voluntad del legislador y la reducción al máximo del arbitrio en la interpretación y aplicación del derecho.

Pero también en el Continente durante el siglo XIX la ciencia del Derecho se desarrolló como ciencia positiva que hace de la ley la piedra angular del sistema. Era el final de un largo proceso, en el que el pluralismo jurídico de la Edad Media, del que nos habla A. J. Arnaud ${ }^{10}$, es sustituido por una concepción -exigida por el Estado Moderno- donde el derecho se reduce a derecho estatal. Dos palabras del legislador -sentenciaría Kirschmanndan al traste con bibliotecas enteras.

Es lógico que, en este contexto, la ciencia del derecho público ${ }^{11}$ se habituara al respeto hacia el dato legislativo, «excluyendo del propio ámbito la legislación, y por tanto, huyendo también de la posibilidad de interferir en la obra del legislador incluso con su actividad interpretativa».

\section{El creciente interés por la Teoría de la Legislación}

Pero los tiempos han cambiado.

Cada vez es más difícil reducir el derecho a derecho estatal: la internacionalización de la vida económica, política y social hace que los Estados nacionales importen cada vez más normas y que el porcentaje de normas que se aplican a sus ciudadanos y que se han producido más allá de sus fronteras sea mayor que las normas de «producción nacional».

${ }^{9}$ Lectures on the relations between law and public opinion in England during the nineteenth century, Reedición en New Brunswick, 1981.

${ }^{10}$ Legal pluralism in the light of normativist approach to Law, The Amsterdam Law Program, 1994. Así como La Critique de la Raison Juridique, I. -Où va la Sociologie du droit (L.G.D.J. París, 1981, págs. 23 y ss.)

${ }^{11}$ Sabino Cassese, op. cit., pág. 309. 
En segundo lugar, la doctrina de la soberanía del Parlamento, tal y como ha sido teorizada tradicionalmente, se compadece mal con la aparición y desarrollo de otras poderosísimas fuentes normativas.

En tercer lugar, el tránsito del Estado liberal al Estado Social: la maduración de los programas de inversiones públicas y de prestación de servicios permite constatar que no siempre el legislador alcanza los objetivos perseguidos, lo que obliga a una evaluación cada vez más refinada de los proyectos.

La creciente insatisfacción de los ciudadanos, en cuarto lugar, ante la «inflación» legislativa o la oscuridad de las normas y la inseguridad que su defectuosa redacción provoca obligan a la doctrina -y a los propios legisladores- a estudiar la eficacia de otras técnicas no normativas de control y de cambio social más eficaces y a articular procedimientos de redacción más respetuosos con los derechos de los ciudadanos.

Me atrevería a sugerir, en quinto lugar, que el proceso de construcción comunitario no es ajeno a esta necesidad crecientemente sentida de reflexión sobre nuestros mecanismos de hacer derecho. En efecto, el cada vez más estrecho contacto de sistemas jurídicos, como el anglosajón y el continental, fruto de la convivencia de ambos sistemas en el seno de la Unión Europea, está produciendo unos problemas inéditos para los que los procedimientos tradicionales de legislación y la Ciencia tradicional del derecho carece de respuesta. El derecho comunitario -casi la mitad de las normas que se aplican a nuestros nacionales son de origen comunitario- es el fruto de un mestizaje de técnicas en el que se mezclan procedimientos de la cultura anglosajona con los procedimientos más peculiares del continente. Todo ello está produciendo una cierta simbiosis, o cuando menos, un evidente acercamiento entre las técnicas, los procedimientos y los puntos de interés de los juristas continentales y británicos. Y, aunque los juristas británicos se preocupan y protestan por la invasión continental del modo de hacer derecho, tampoco les faltan razones a los nacionalistas franceses -pongamos por ejemplo- para ponerse en guardia frente al influjo sobre la Unión Europea de las técnicas británicas. El relativamente reciente interés del Continente por los problemas de técnica legislativa se ve acrecentado así por la incidencia británica y la lógica importación al Continente de los estudios que los británicos dedican a la Legislación.

Luzius Mader ${ }^{12}$ resume todo este ambiente en dos causas que explican este nuevo interés por la producción de normas:

«Por una parte, el creciente interés por la legislación refleja en mi

\footnotetext{
${ }^{12}$ Luzius Makder, La legislation: objet d'une science en devenir?, en La science de la legislation, en Travaux du Centre de Philosophie du Droit, PUF, París, 1988.
} 
opinión la transformación profunda tanto del papel del Estado en la sociedad como el papel del derecho -y particularmente de la ley- en tanto que medio de acción o de instrumento de regulación estatal. La legislación se ha convertido en una actividad problemática: prolífica, lenta, liberticida e ineficaz; así es como la consideran muchos ciudadanos. Y esto es lo que ha llevado a los juristas a interrogarse sobre la creación de las normas legales, sobre su puesta en aplicación y sobre sus efectos».

Por otra parte, el nuevo interés por el fenómeno legislativo es también debido a la influencia de cambios que se han operado en otras ciencias sociales, en particular en sociología jurídica, ciencias políticas y administrativas que (ibídem) «ponen de relieve la flagrante falta de conocimientos sobre aspectos importantes del fenómeno legislativo así como el carácter ampliamente artesanal de la fabricación de las leyes. Han contribuido aquéllas así a crear... las condiciones para el aliciente de una verdadera ciencia de la legislación».

Estos son algunos de los factores que explican porqué la ciencia jurídica que durante siglos ha sido Jurisprudencia, en la acepción de Austin, vuelve a ocuparse de la Legislación, a interesarse por la creación de las normas y la relación de estas con la realidad social.

\section{La institucionalización de los estudios de Legislación}

El interés por la legislación no es, como hemos señalado, de hoy. La nómina de teóricos del derecho que se han ocupado en otros tiempos de los problemas de la Legislación es abundante. Pero lo que caracterizaba hasta hace poco este tipo de estudios era su desconexión, asistematicidad y discontinuidad.

Si la existencia del Office of Parliamentary Counsel en Inglaterra ha hecho posible, desde el pasado siglo, la existencia de unos artesanos de la legislación y, en su entorno, de una reflexión sobre métodos y técnicas de legislar, en el Continente el auténtico cambio de rumbo en la materia se produce en torno a los 70 .

Es en la década de los 70 cuando han madurado ya los programas sociales que se inician en la postguerra y se comienza a percibir que los frutos de los mismos no tenían ni la incidencia que habían augurado sus promotores ni los efectos negativos con que habían amenazado sus detractores. La experiencia permitía, y obligaba a evaluar los resultados de las normas: los efectos queridos pero no producidos y los no queridos pero producidos.

Es entonces cuando se produce la decisiva obra de Peter Noll ${ }^{13}$ "Gesetzsgebung» de 1973 que ha dado origen al surgimiento de una

${ }^{13}$ Peter Noll, Gesetzsgelunglehre, Rowoohlt, Hamburg, 1973. 
impresionante literatura, de aportaciones individuales y colectivas, a la aparición de revistas especializadas en numerosos países como Legislation d'aujourd'hui en Suiza, en Alemania Zeitschrift für Gesetsgebung, Zeitschrift für Rechtspolitik, Kritische Vierteljahrssrift für Gesetzgebung und Rechtwissensschaft, en Portugal la revista Legislaçao, Statute Law Review en Ingaterra, ect.

En el plano europeo, comienzan a aparecer organismos e instituciones dedicados a los estudios de legislación.

Existe ya una Asociación Europea de Legislación, creada a raíz de la Conferencia sobre Legislación en los países europeos, celebrada en los días 11 a 13 de diciembre de 1991 en Alemania. También hay que citar el Servicio de la Gestión Pública de la OCDE (París).

En Inglaterra, se dedican a estos estudios el Royal Institute of Public Administration (RIPA) de Londres, el Office of Parliamentary Counsel, el Civil Service College, la Statute Law Society así como el Instituto de Criminología de la Universidad de Cambridge, el Centro de Criminología y de Estudios filosóficos y sociológicos del derecho de la Universidad de Edimburgo, y los centros socio-legales de las Universidades de Sheffield y de Oxford ${ }^{14}$.

En Bélgica ${ }^{15}$, como instituciones que se ocupan del tema hay que citar el Centrum voor Rechtssociologie de la Universitaire Faculteiten Sint-Ignatius de Antwerpen, así como la Facultad de Derecho, de Economía y de Ciencias Sociales de la Universidad de Lieja.

En Holanda ${ }^{16}$ la preocupación por la calidad de las leyes ha llevado a atribuir al Ministerio de Justicia el objetivo de cuidar de la calidad de las leyes (con la creación en su seno en 1987 del Committee for the Review of Legislative Projects así como la General Legislation Policy Division) con un doble cometido: el desarrollo de una política general en materia de legislación (con la elaboración de unas Directions for Legislation y el Legislative Procedure Handbook) y el análisis, caso a caso, de la calidad de las leyes.

En Francia, los estudios de técnica legislativa se realizan en la Ecole National d'Administration (ENA).

En Alemania ${ }^{17}$, existe la Hochschule für Verwaltungswissenschaften (HFW) Speyer, la Gessellschaft für Rechts und Politik, y la Gessellschaft für Förderung der

\footnotetext{
${ }^{14}$ Keith Patchett «La science et la legislation en Grand-Bretagne» en «La science de la legislation», op. cit.

${ }^{15}$ Philippe Gerard, «La science de la legislation en Belgique. Bilan et perspective» en «La science de la Legislation», op. cit.

${ }^{16}$ J. H. van Kreveld, «The role of the Ministry of Justice in the Dutch legislative process». Texto mecanografiado.

${ }^{17}$ Valentin Petev: «Reflexions sur la science de la legislation en Allemagne Federale» en «La science de la legislation», op. cit.
} 
Entbürokratisierung. 
En Italia, se ha creado un Observatorio legislativo Interregional ${ }^{18}$. Desde 1988 el Instituto para la Documentación y los Estudios legislativos (ISLE) organizó una Escuela de Ciencia y Técnica de la Legislación que viene dando cursos $^{19}$. La preocupación por la proliferación de leyes, su rápida reforma, su fragmentación y estratificación, sus ambigüedades y su defectuoso lenguaje, con la consiguiente quiebra de la certeza jurídica, se plasmó incluso en la ley $n^{\circ} .400$ de 25 de agosto de 1988 cuyo articulo 23 preveía la constitución de un Departamento central para la coordinación de la iniciativa y de la actividad normativa del Gobierno ${ }^{20}$.

El interés sobre estos temas en Canadá y en Australia ha dado lugar a importantes trabajos al respecto tanto en sede parlamentaria como en la Administración y la Universidad.

Por lo que se refiere a España, no se debe olvidar la labor de la Comisión General de Codificación, único órgano especializado de producción normativa. En cuanto a los estudios de técnica legislativa

${ }^{18}$ Forman parte de este Observatorio representantes de los Gobiernos regionales, ambas Cámaras, Presidencia del Consejo, el Instituto para la Documentación Jurídica del Consejo Nacional de Investigación, el Instituto de Estudios sobre las Regiones, con la contribución del Instituto para la Documentación y los estudios legislativos.

Este Observatorio consiguió elaborar en 1992 unas Reglas y sugerencias para la redacción de las leyes referidas a:

- lenguaje normativo: extensión de los periodos y modos de los verbos, elección y utilización de los términos, definiciones, homogeneidad terminológica, etc.;

- reglas de redacción de las leyes respecto al uso de abreviaturas, citas, signos de puntuación, etc.;

- estructura del acto normativo: elementos del texto, partes, título, homogeneidad terminológica entre texto y título, división del texto, párrafos, subdivisiones...

- reglas para las remisiones y reformas.

${ }^{19}$ Mario D'Antonio, «A crise da legislaçao em Italia: as orientaçoes corretivas publicas $e$ privadas para una melhor elaboraçao técnica das leis», en Legislaçao $\mathrm{n}^{\circ} .7$, abril-junio 1993.

${ }^{20}$ El texto de la ley dice así: «El Departamento indica al Presidente del Consejo de Ministros y a los Ministros interesados a través de informes periódicos las incongruencias y antinomias normativas referidas a los diversos sectores legislativos; señala la necesidad de proceder a la codificación de materias enteras o a la redacción de textos únicos. Tales informes serán enviados por la Presidencia del Consejo de Ministros a la Presidencia de la Cámara de Diputados y a la Presidencia del Senado de la República».

Esta ley fue desarrollada por el Decreto del Presidente de la República de 19 de junio de 1989 precisando las competencias y encargando al nuevo Departamento la tarea de «proceder a la revisión técnico-formal de los proyectos de redacción de las leyes y demás actos normativos». Pero según Mario d'Antonio (ibid.) el Decreto en cuestión ha encontrado graves dificultades de implementación por lo que sus resultados no deben ser demasiado alentadores. 
son, lógicamente, muy jóvenes y no han hecho sino comenzar. De vez en cuando se organizan cursos (Centro de Estudios Constitucionales) y seminarios (Congreso de los Diputados y Asambleas y Comunidades Autónomas). Se han publicado algunos importantes trabajos (como los del Grupo GRETEL) y comienza a disponerse de una bibliografía básica sobre la materia ${ }^{21}$. Todavía, sin embargo, las Universidades no incluyen estudios de logística en sus curricucula y, en cuanto a las medidas institucionales adoptadas ${ }^{22}$, no son más que el inicio de un proceso que debe continuarse. Es de esperar -como señala Nicolás López Calera $^{23}$ - que «una vez pasada esta etapa política de transcribir y consolidación democrática en la cual lo que está en juego son los aspectos fundamentales de un orden social y jurídico avanzado, se desarrollen con fuerzas las preocupaciones propias de la ciencia de la legislación que están surgiendo con timidez».

\section{4. ¿Qué puede aportar el estudio de la teoría de la Legislación?}

De entre los objetivos que debería perseguir la renovación de los estudios sobre legislación, destaco los siguientes:

A) Reforzar el principio democrático

Se trata de reivindicar que la ley, en cuanto decisión del órgano representativo, es y tiene que ser el criterio relevante a la hora de determinar el modelo de conducta debido y de decidir controversias concretas. Algo que se ha puesto en cuestión tanto práctica como teóricamente.

${ }^{21}$ A los trabajos del Grupo Gretel como su Curso de técnica legislativa publicado por el CESCO en 1989, hay que añadir La calidad de los leyes (Colección informes y documentos del Parlamento Vasco), La Técnica normativa de las Comunidades Autónomas (Comunidad de Madrid, 1991). La técnica legislativa a debate (Corona/Pau/Tudela, Tecnos, Madrid, 1994), etc.

${ }^{22}$ Instrucciones para la tramitación de asuntos en los órganos colegiados del Gobierno (Acuerdo del Consejo de Ministros de 29 de diciembre de 1989), Cuestionario de Evaluación que deberá acompañarse a los proyectos normativos que se elevan al Consejo de Ministros (Acuerdo del Consejo de Ministros de 26 de enero de 1990), Directrices sobre la forma y la estructura de los anteproyectos de ley (Acuerdo del Consejo de Ministros de 18 de octubre de 1991), a los que deben añadirse la Ley Procedimiento Administrativo, la Ley del Régimen Jurídico de las Administraciones Públicas y del Procedimiento Administrativo Común, algunas leyes de Presupuestos y la normativa de desarrollo.

${ }^{23}$ Nicolás López Cabeza, La science de la Legislation en Espagne. Realisations et necesité, en La Science de la legislation, op. cit., pág. 79. 
En efecto, la inflación normativa, la incomprensibilidad del tenor de la norma, la baja calidad de ésta, el cambio del contexto social en que se ha de aplicar, junto con la pérdida de protagonismo y prestigio de las instituciones parlamentarias son factores que se aducen para justificar que el juez abandone, con excesiva precipitación, el texto normativo para buscar, fuera del mismo, el criterio para resolver el problema en cuestión.

Buena parte de la teoría del derecho del presente siglo ha dedicado sus mejores esfuerzos a poner de relieve la imposibilidad de que la regla del derecho pueda dar respuesta a todas las situaciones concretas a que se enfrentará el aplicador de la norma.

Que no es posible que el legislador prevea en sus mínimos detalles todas las situaciones reales a que se enfrentará el aplicador de una norma se debe -como señala $\mathrm{H}$. L. A. Hart ${ }^{24}$ - a nuestra relativa ignorancia de los hechos a la relativa indeterminación de propósitos del legislador y a las propias limitaciones del lenguaje. El formalismo jurídico, navegando por el «paraíso de los conceptos», no percibió la inevitable «textura abierta» de las normas que hace que, en la práctica, la interpretación en determinados supuestos es una elección entre alternativas abiertas.

Pero una cosa es afirmar dicha textura abierta de las normas y otra muy distinta el escepticisino ante las reglas que desde principios de siglo y a partir de la escuela del derecho libre ${ }^{25}$ parece haber ido dominando el método y, por tanto, incluso la propia teoría de las fuentes.

Pero como dice H. L. A. Hart, «Formalismo y escepticismo ante las reglas son el Escila y el Caribdis de la teoría jurídica; son grandes exageraciones que resultan saludables cuando se corrigen entre sí» ${ }^{26}$.

Y tengo la impresión de que el escepticismo ante las reglas es en estos momentos el escollo que conviene corregir. Que con excesiva frecuencia el aplicador del derecho no se mueve en las zonas marginales en las que el legislador le delega competencias normativas (facultándole para una elección informada entre alternativas abiertas) sino que trata simplemente de crear la norma, destilándola a partir

\footnotetext{
${ }^{24}$ El concepto de Derecho, Abeledo-Perrot, Buenos Aires, 1968, pág. 160.

${ }^{25}$ Alf Ross, Hacia una ciencia realista del Derecho, (Abeledo-Perrot, Buenos Aires, 1961, pág. 166): la escuela del derecho libre «... a expensas del legislador hace resaltar la importancia de otras varias fuentes, que expresan las consideraciones de propósitos libremente seguidos (por ejemplo, consideraciones independientes del texto legal), tal como la justicia, la equidad, la idea del derecho, el derecho natural, el derecho como recurso sociológico, el sentido de la justicia, el equilibrio de intereses, etc.»

${ }^{26}$ Hart, op. cit., pág. 183.
} 
de los más heterogéneos componentes que su imaginación aporta y entre los que, eso sí, figura la ley.

Un Estado de Derecho no puede aceptar, sin poner en peligro sus propios fundamentos, que las leyes sean un simple criterio, junto con otros criterios, para decidir el caso controvertido: La ley ha de ser el criterio relevante. Así se deduce de ese principio metajurídico, de ese ideal ético-político que es el imperio de la ley, que, como señala Francisco Laporta $^{27}$ «tiene efectivamente como objetivo establecer en su ámbito las condiciones de posibilidad de la autonomía individual» que... «sólo es posible en un contexto social regulado, es decir, sometido a normas. Un contexto social asaltado inesperadamente por decisiones súbitas e imponderables minimiza las posibilidades de la autonomía del individuo para hacer planes de vida. Los juristas liberales tienden al normativismo; los juristas antiliberales tienden al decisionismo». Este principio del imperio de la ley, resume Francisco Laporta, supone que «el ordenamiento jurídico debe vertebrarse en torno a un conjunto de normas emitidas por una autoridad reconocida, genelares, prospectivas, estables, claras y ciertas».

$\mathrm{Y}$ esa es una de las aportaciones de la ciencia de la legislación: ayudar a que se dicten aquellas normas que sean necesarias y sólo las necesarias y a obtener leyes más claras, eficientes y eficaces.

La defensa, en suma, del imperio de la ley, en un Estado democrático de derecho, obliga a articular las técnicas que eviten, al máximo posible, aquellas situaciones que «justifican» eludir el texto normativo; técnicas que hagan que la ley por su claridad, certeza, precisión, estabilidad, eficiencia, etc., pueda realmente ser el criterio relevante para determinar la conduta debida de ciudadanos y aplicadores del derecho.

B) Facilitar la interpretación

Hay una evidente relación entre la doctrina de las fuentes del derecho y la teoría del método $^{28}$. Para la teoría positivista -que hace de la ley la fuente principal del derecho- la interpretación consiste en establecer, por métodos lógicos, la voluntad del legislador. Para la Escuela del derecho libre -que rechaza reducir el derecho a la ley- la interpretación supone «pensar plenamente» la ley en armonía con el principio inmanente del derecho.

${ }^{27}$ Francisco Laporta, El imperio de la ley: un marco analítico. Texto mecanografiado.

${ }^{28}$ Alf Ross, Sobre el derecho y la justicia, Temas Eudeba, Buenos Aires, 1970, pág. 149. 
Si el principio del imperio de la ley de un Estado de Derecho impide el escepticismo ante las reglas y obliga a hacer de la ley el criterio relevante de decisión, como hemos indicado, es preciso señalar que no cabe una teoría de la interpretación seria si se prescinde del estudio riguroso del proceso legislativo o en palabras de Elías Díaz, no cabe magistratura democrática sin Legislatura democrática. Dicho utilizando la terminología de Austin, no cabe Jurisprudencia sin Legislación. Y ello, al menos, en un doble sentido:

1. Es necesario dar un mayor peso a los antecedentes legislativos en la interpretación y aplicación de las normas.

Es cierto que, como reflejo de la metodología positivista imperante, se ha ido históricamente imponiendo la teoría de la interpretación objetiva (que centra su consideración en la llamada voluntad de la ley) sobre la subjetiva (que trata de indagar los propósitos del legislador).

Las razones que se han alegado para ello estriban en que ceñirse a la voluntad del legislador: a) ancla la interpretación a un pasado que muy poco tiene, a veces, que ver con los problemas de la sociedad presente, mientras la interpretación objetiva ofrece esa flexibilidad que permite mantener con vida el texto, y b) evita el problema de determinar si los órganos colegiados tienen voluntad y, en su caso, si esta es identificable.

Uno de los elementos que diferencia a la interpretación subjetiva de la objetiva (se trata de dos estilos más que de dos métodos) es el papel asignado a los antecedentes de la ley. Si lo que se trata de descubrir es, como pretende la interpretación subjetiva, el significado que intentó expresar el legislador, el estudio de los antecedentes legislativos es esencial. La interpretación objetiva al tratar, por su parte, de llegar a conocer el significado de la ley tal y como está comunicado en el texto, no precisa conocer dichos antecedentes. El artículo 3.1 de nuestro Código Civil, según el prof. Luis Diez Picazo ${ }^{29}$ «se orienta significativamente hacia la dirección objetiva».

Pero me atrevería a sugerir que el principio democrático exige a la doctrina un replanteamiento del problema; a dar un mayor protagonismo a la voluntad de un legislador que ha sido legitimado por la voluntad de los ciudadanos para imponer pautas de comportamiento obligado.

${ }^{29}$ Sistema de Derecho Civil, Vol. I, Tecnos 1990, pág. 186 
Por ello el artículo 3.1 de nuestro Código Civil se debe interpretar, a su vez, de acuerdo con nuestra nueva realidad democrática: que es necesario indagar la voluntad del legislador y hace de la misma, allí donde ésta sea identificable, el criterio prioritario de interpretación de las normas. El estudio de las palabras utilizadas, del contexto, de los antecedentes históricos y legislativos así como de la realidad social en que han de ser aplicados no pueden ser más que un instrumento para alcanzar el primer objetivo de la interpretación en el Estado de Derecho: conocer la voluntad del legislador. Y sólo la imposibilidad de conocer, en el caso concreto, aquella voluntad puede justificar que ésta no sea el criterio prevalente.

Es cierto que se ha cuestionado la posibilidad de que los órganos colegiados puedan tener una voluntad o que, aun aceptando que ésta exista, sea posible conocerla. Ciertamente se trata de una convención que la ciencia del derecho aplica a todas las personas jurídicas (sociedades, asociaciones, partidos, etc.).

Como son convenciones las principales premisas sobre las que se asienta la democracia: son convenciones absolutamente imprescindibles para la salvaguardia de las libertades. Que el Parlamento tiene voluntad es otra convención indispensable para el correcto funcionamiento del sistema, que puede, y debe incidir, en el método o estilo de interpretación.

Claro está que, aún aceptada la relevancia de la voluntad del legislador en la tarea interpretativa, surgirá el problema de cómo compatibilizar la voluntad del legislador histórico con un legislador actual que puede representar intereses y perspectivas diferentes. El problema no ha sido nunca, ni lo es hoy en día, fácil de resolver, pero incluso en este supuesto el estudio del proceso normativo, de la estructura y funcionamiento de las instituciones normativas ofrecerá al intérprete asideros más seguros y fiables que el puro decisionismo judicial o la construcción de una lógica del derecho pretendidamente aséptica, al margen de la ciencia política. En suma, y como señala Pablo Salvador $\operatorname{Coderch}^{30}$. «En el camino hacia las ciencias sociales no hay que ver ni temer disolución del derecho en política, sino no hay que ver ni temer disolución del derecho en política, sino avance a una mejor, pero nunca acabada explicación de los problemas que siempre han ocupado al intérprete doctrinal...».

Es preciso, pues, corregir la orientación fundamentalmente objetiva con que la doctrina ha interpretado el artículo 3.1 del Código Civil sin, por ello, refugiarse en el activismo judicial que convierte las preferencias de los jueces en el criterio relevante a la hora de interpretar las normas $\mathrm{y}$, para ello, es precios dar mayor relevancia al

\footnotetext{
${ }^{30}$ Pablo Salvador Coderdi, Interpretación judicial y decisión política, Anuario de Derecho Civil, tomo XLV, fascículo IV, octubre-diciembre, 1992, pág. 1598.
} 
estudio de la voluntad del legislativo. Y algo de esto es lo que, al parecer, se insinúa ya en España. Pese a las reticencias de la doctrina respecto a la búsqueda de la voluntad del legislador ${ }^{31}$ y como expresión de la realidad democrática, la interpretación objetiva ha tenido que ir haciendo concesiones a la teoría subjetiva:

- Se citan los trabajos parlamentarios e incluso normas que todavía no han entrado en vigor $^{32}$.

- Se usan las Exposiciones de motivos y, cada vez más, las disposiciones directivas.

- Y el propio Tribunal Constitucional fundamenta a veces sus decisiones en los trabajos parlamentarios ${ }^{33}$.

${ }^{31}$ Antonio Cuerda, El legislador y el derecho penal. Una orientación a los orígenes. Editorial Centro de Estudios Ramón Areces, 1991, pp. 88 y ss.

32 Vide: Aulis Aarnio «Lo racional como razonable» (Centro de Estudios Constitucionales, Madrid 1991, págs. 123 y siguientes) a propósito del valor de los trabajos parlamentarios como fuente.

Asimismo, la Sentencia de la Sala $3^{a}$. del T. Supremo de 1-12-1992, ante la solicitud de indemnización de un Magistrado, por el adelanto de la edad de jubilación provocado por el legislador ordinario dice así en su Fundamento $8^{\circ}$. «Por último, la Ley de Régimen Jurídico de las Administraciones Públicas y del Procedimiento Administrativo Común, ... no vigente pero orientativo de la voluntad del legislador al regular por primera vez esta materia, limita la indemnización a los particulares por la aplicación de actos legislativos de naturaleza no expropiatoria de derechos en un triple aspecto: $1^{\circ}$. -que no tengan el deber jurídico de soportarlo, $2^{\circ}$. -que se establezca en los propios actos legislativos y $3^{\circ}$. -que la indemnización tendrá lugar en los términos que se especifiquen en los propios actos ...», por lo que concluye que no ha lugar a la indemnización solicitada).

Por su parte, la Sentencia 5-10-92 de la Audiencia Provincial de Madrid. secc. $2^{\mathrm{a}}$. dice lo siguiente: «El artículo 2-3 . de la Ley Orgánica 8/1984 condena claramente «al que rehusare cumplir la prestación social sustitutoria» y tanto en su letra, como en su espíritu está supeditando el deber moral o de conciencia al cumplimiento de aquella obligación legal. De los trabajos Preliminares de la Ley, debates parlamentarios y conjunto de antecedentes, no puede menos que concluirse que el legislador se planteó, discutió y tuvo presente toda la problemática suscitada acerca de la posibilidad apuntada por algunos sectores parlamentarios de implantar un ejército profesional y voluntario. El legislador, sin dejar de prever las consecuencias, optó por imponer un servicio militar obligatorio... La consecuencia ineludible, desde esta perspectiva jurisdiccional, es que cuando la ley efectúa la valoración de bienes en conflicto no le es dable al Juzgador alterar el orden de valores en ella impuestos, máxime teniendo en cuenta que nos encontramos en un estado social y democrático de derecho, con un principio de separación de poderes, en el que aquella alteración de valores por parte del Juzgador implicaría una extralimitación de la tarea interpretativa de la ley para entrar de lleno en una función normativa que no le es propia».

${ }^{33}$ Sentencia 2/1981 de 30 de enero: el principio non bis in idem, no expresamente recogido en el artículo 9.3 de la Constitución, tiene carácter constitucional porque «lo entendieron los parlamentarios en la Comisión De Asuntos Constitucionales y Libertades públicas del Congreso de los Diputados... íntima- 
Para que esta reorientación, o al menos reequilibrio, de la doctrina sea efectiva, la teoría de la legislación ha de ocuparse con mayor detenimiento del proceso legislativo y, por consiguiente, de los problemas de técnica legislativa.

2. Es preciso prevenir, en la medida de lo posible, los fallos del proceso legislativo que dificultarán la interpretación de la normas.

Las dificultades más importantes de la interpretación de las normas se producen en el propio proceso legislativo. William Twining and David Miers ${ }^{34}$, al estudiar los problemas que surgen en la interpretación proponen al intérprete un modelo de Checklist para detectar dónde y cómo se han producido las condiciones generadoras de las dudas. Porque los problemas a que se enfrentará el intérprete han sido ordinariamente provocados:

a) En la fase previa a la redacción de la norma, por una aprehensión errónea, incompleta o inadecuada del contexto y de los hechos, por una categorización inapropiada del problema a resolver por el legislador, por la falta de objetivos políticos claros, o por ser éstos contradictorios o inconsistentes, porque se ha pretendido resolver con una norma lo que hubiera requerido otro tipo de instrumentos de gestión, o porque el sistema institucional vigente dificulta o imposibilita la correcta solución.

b) En la fase de redacción de la norma, provocando dudas en torno a la intención del legislador (sentido de las palabras, ámbito que se quiso cubrir, efectos deseados, consecuencias pretendidas, razones para dictar la norma), o sobre la relación de la norma con el resto del sistema, o de otro sistema, o por la elección de unos medios inadecuados para implementar los objetivos, o debido a una redacción defectuosa (por la organización del texto, la elección de palabras y términos inapropiados, la existencia de lagunas, oscuridad intencional, inconsistencia interna, etc.) por una delegación deliberada de potestades normativas (uso de términos vagos, conceptos indeterminados), por urgencias indebidas en la tramitación de las normas, etc.

mente unido a los principios de legalidad y tipicidad de las infracciones recogidas principalmente en el art. 25 de la Constitución», como se puso de relieve en la intervención de Pérez Llorca con ocasión del articulo 9.3, anunciando su disposición a tratarlo en el artículo 25. Pero en el articulo 25... se les olvidó a los constituyentes.

${ }^{34}$ How to do things with rules, Weidenfeld and Nicolson, $2^{\mathrm{a}}$. ed. Londres. 
c) En la fase de decisión gubernamental, el Gobierno puede generar zonas de dudas en las normas cuando descuida el cumplimiento de determinados requisitos procedimentales de los que puede depender la propia validez de la norma; o cuando para edulcorar determinadas medidas que pueden recibir un rechazo parlamentario o social utiliza una terminología ambigua, o cuando recurre sin necesidad al uso de conceptos indeterminados, etc.

d) En la fase parlamentaria de aprobación de una norma, las necesidades de lograr determinadas mayorías o alcanzar un consenso pueden dar lugar a cambios en la redacción que provoquen más ambigüedad, que disminuyan la claridad del primitivo texto, que generen antinomias o lagunas mediante enmiendas, de última hora o poco meditadas, que alteren la lógica del texto.

e) En la fase de publicación de las normas, se pueden generar un conjunto de dudas suscitadas por erratas que se producen no sólo a lo largo del proceso legislativo (son muchas manos las que reescriben muchas veces las sucesivas versiones de un proyecto), sino en la misma fase de publicación (las erratas de imprenta).

Es, pues, ahí -en el proceso legislativo- donde se producen algunas de las causas de oscuridad de las normas y de los problemas que ha de resolver posteriormente el intérprete. $Y$ no parece razonable que la teoría del derecho renuncie a intervenir en esta fase ayudando al legislador a una elaboración más cuidadosa de las normas, evitando preventivamente aquellos errores que, de otro modo, tendrán que resolver posteriormente los jueces.

De la misma forma que la mejor política sanitaria es la preventiva, la mejor política interpretativa es una buena política legislativa.

C) Mejorar la formación de los juristas

Por último, hay que referirse a los aspectos pedagógicos porque el olvido de los problemas derivados del proceso legislativo supone una mutilación en la formación de unos juristas que, en algunos supuestos, no sólo se dedicarán a interpretar normas sino también a producirlas: aquello que van a producir es, curiosamente, lo que no se les ha enseñado a hacer.

El manifiesto «Pour une nouvelle génération de légistes» ${ }^{35}$ que se hizo en 1979 en Bélgica solicitando la creación de un Instituto Belga de Legística se fundamenta en esta constatación: «La actual formación

${ }^{35}$ Journal des tribunaux, 17 de noviembre de 1979. 
jurídica está esencialmente reducida a la aplicación del derecho, es decir, a la apreciación de los comportamientos sociales (pasados o futuros) en su relación con la reglas ya existentes; es una equivocación que permanezca oculta en la formación jurídica la otra cara del derecho, que se refiere a la invención de reglas aptas para orientar los comportamientos sociales en el sentido querido por el poder político». Por eso, afirma Fleiner-Gerster ${ }^{36}$ «la formación legislativa no debería ya limitarse a formar buenos jueces y buenos abogados si no que se debería igualmente enseñar el arte de hacer buenas leyes». Claro está que, como sugieren C. E. Alchourrón y E. Bulygin ${ }^{37}$ «no hay especialistas o técnicos en la legislación por la sencilla razón de que no hay centros académicos que la preparen y no los hay porque no existe un cuerpo de doctrina, es decir una teoría que estudie sistemática y metódicamente los problemas que plantea la legislación y el modo de resolverselo».

\section{El contenido de una disciplina sobre la Legislación}

¿Cómo hacer buenas leyes?

Se han propuesto diferentes modelos de racionalización del proceso legislativo entre los que citaríamos los de Peter Noll, J. Wroblewsky ${ }^{38}$, Mario Losano ${ }^{39}$, Martin Casals ${ }^{40}$ o Manuel Atienza.

En casi todos ellos se echa en falta, por una parte, una más clara diferenciación entre la planificación normativa y la redacción del anteproyecto de norma. La mayoría de los modelos obvian el momento de la planificación donde no es infrecuente que quiebre la «racionalidad» del proyecto normativo antes incluso de iniciarse su redacción: es en la fase donde, detectado un problema, una defectuosa evaluación de sus causas y unas erráticas instrucciones al redactor puede marcar con la irracionalidad los ulteriores trámites del proceso. Si se falla en este cometido, de poco servirán al respecto los restantes criterios de racionalidad: estaremos en presencia de una mala ley.

${ }^{36}$ Fleiner-Gerster, Informe introductorio al $12^{\circ}$. Coloquio sobre Principios y Métodos de elaboración de Normas celebrado en Friburgo en octubre de 1982, op. cit., pág. 18.

${ }^{37}$ Análisis lógico y derecho, Centro de Estudios Constitucionales, Madrid, 1991, pág.410.

${ }^{38}$ A model of rational Law-Making, ARSP, t. I, XV/2, 1979; Rational Law-Maker and Interpretative Choices, RIFI, IV-I, XII, I, 1985.

${ }^{39}$ Analisi empirica e analisi delle procedure giuridiche, en Societá, norme e valori. Studi in onore di Renato Treves, Ed. de U. Scarpelli y V. Tomeo, Giuffré, Milano, 1984.

${ }^{40}$ Curso de Técnica Legislativa, CESCO, Madrid, 1989. 
Por otra parte, es absolutamente necesario, de acuerdo con Bennion ${ }^{41}$ diferenciar entre la fase de redacción y la fase de validación (gubernamental y parlamentaria) de la norma. Ni el Gobierno ni el Parlamento redactan normalmente los proyectos del ley. Los redactan expertos y los debaten y aprueban los órganos políticos competentes.

Ello nos llevaría a sistematizar el complejo proceso legislativo en las siguientes fases: planificación de la intervención, redacción del proyecto, validación gubernamental del mismo, aprobación por las Cámaras, publicación y evaluación del impacto.

\section{Planificación normativa:}

Es una fase donde se producen los impulsos normativos, previa a la iniciativa legislativa o reglamentaria en la que juegan un papel capital los ciudadanos, grupos de interés, grupos de presión, medios de comunicación, partidos políticos, Tribunal Constitucional, Consejo General del Poder Judicial, Tribunal de Cuentas, etc., que demandan la promulgación de una norma.

Es también la fase donde el Gobierno, y en menor medida los partidos, seleccionan las demandas mediante los programas electorales y/o de gobierno.

Es la fase en la que, en el proceso normal, el Gobierno encomienda el análisis de las causas del problema, examina las alternativas no normativas a su disposición y finalmente, y en el supuesto de que recurra a la producción de una norma, fija los objetivos de la misma dando instrucciones al respecto al experto que redactará el anteproyecto.

\section{Redacción del proyecto:}

Se trata del momento de redacción de la norma por parte del experto encargado y en el que las técnicas legislativas pueden suponer una clara mejora de la calidad de las normas. Es el momento donde, de una forma especial, se ha de cuidar la racionalidad lingüística, pragmática, sistemática y teleológica.

Esta fase termina con la entrega del anteproyecto al responsable político que comprobará si se han cumplido las instrucciones y alcanzado los objetivos propuestos.

${ }^{41}$ Francis Bennion, Statute Law, Oyez, 1980 


\section{Validación gubernamental:}

Es la fase en la que los órganos gubernamentales competentes (las Comisiones Delegadas, la Comisión de Secretarios de Estado y de Subsecretarios así como, finalmente, el Consejo de Ministros) examinan el borrador de norma y, en su caso, aprueban su remisión a las Cámaras.

\section{Aprobación parlamentaria:}

Se trata de la fase capital desde la perspectiva de la legitimación de la norma, en la que las Cámaras debaten el proyecto de ley y le dan su forma definitiva.

\section{Evaluación del impacto:}

Convertido el proyecto en norma, se ha de proceder a evaluar su impacto, su eficacia y efectividad, examen que permite, a su vez, volver a iniciar el proceso normativo.

En todo este proceso normativo participan, como hemos podido ver, numerosos sujetos: ciudadanos u organismos que piden la intervención de los poderes públicos ante un problema; expertos que analizan el problema, sus causas y las posibles alternativas; responsables políticos que deciden intervenir y establecen unos objetivos; profesionales que redactan un borrador; Gobierno que aprueba el anteproyecto y Cámaras que debaten su contenido y deciden el texto definitivo de la ley. ¿Es posible racionalizar todo este proceso? ¿Puede, y debe, todo este complejo mecanismo ser estudiado por una disciplina autónoma?

Si a partir de P. Noll la legislación, en el Continente, se convirtió en objeto autónomo de conocimiento y estudio, la disciplina que se abre paso se caracteriza por la heterogeneidad de los campos de investigación y de métodos (tomados en prestamo a otras ciencias, hecho que, por otra parte, convierte a la teoría de la legislación en una disciplina profundamente ecléctica) que precisa el concurso de la teoría oeneral del derecho, del derecho administrativo, del derecho constitucional, del derecho parlamentario, de la sociología del derecho, de la lingüística, de la economía política... y un largo etcétera.

Por qué -se pregunta Luzius Mader ${ }^{42}$ - reunir forzosamente los

\footnotetext{
${ }^{42}$ Op. cit. p. 16.
} 
diferentes campos de investigación y las diferentes perspectivas de investigación bajo una misma etiqueta: La explicación más plausible es que la combinación de todas las perspectivas señaladas nos permitirá no sólo una mejor comprensión del proceso de gestación de las normas, sino una mayor calidad formal y material de las mismas y, con ello, una mejor interpretación de aquellas.

La polémica sobre si es esta una ciencia o no es un debate poco útil ${ }^{43}$. En todo caso, es cierto que este tipo de estudios oscila entre lo que Jerzy Wroblewsky ${ }^{44}$ denomina enfoque minimalista y el enfoque maximalista:

a) «La ciencia minimalista de la legislación está constituida por las evaluaciones y las normas instrumentales. Se hace la elección de medios jurídicos para alcanzar unos fines presupuestos que no se discuten... El campo de la ciencia de la legislación se reduce a una técnica».

b) La perspectiva maximalista hace de los valores, de los fines que se persiguen el objeto de estudio: trata de determinar también los fines y evalúa los medios teniendo en cuenta los valores de los mismos. En este enfoque, la ciencia de la legislación -si lo que se trata es de determinar el contenido de las leyes- aparece como política legislativa o como ética.

Hoy en día prima el primer enfoque que hace de los estudios de legislación una disciplina más pragmática que busca la racionalidad instrumental ${ }^{45}$ de la norma como realización de una voluntad política; esa racionalidad lingüística, sistemática, pragmática y teleológica que postula Manuel Atienza para el proceso legislativo ${ }^{46}$.

Sea o no la «racionalidad» el término más adecuado al respecto lo que diferencia los enfoques minimalista y maximalista de este

\footnotetext{
${ }^{43}$ Pero la consideración de estos estudios como ciencia, la posibilidad hoy en día de una Ciencia de la Legislación es puesta en cuestión por ejemplo por Jean-François PERRIN «Possibilites et limites d'une science de la legislation» en «La science de la legislation», París, 1988, PUF, aun cuando abogue claramente por la profundización de estos estudios interdisciplinares sobre la legislación y elaboración de normas... «pero sin empeñarse (ibídem, pág. 34) en encontrar una denominación global para el conjunto de estas actividades de investigación». Tal vez con los años, piensa Perrin, se podrá elaborar por inducción una teoría de la legislación que trate de la coordinación necesaria entre los diferentes saberes en este campo.

${ }^{44}$ Conclusiones a La science de la legislation: op. cit., pág. 105 y ss.

${ }^{45}$ Philippe Gerard, «La science de la legislation en Belgique. Bilan et Perspectives», op. cit.

${ }^{46}$ Teoría y Técnica de la Legislación, en Theoría 1987-88; Lenguaje, lógica jurídica y teoría de las normas, en Técnica normativa de las Comunidades Autónomas (Comunidad de Madrid, 1991); Tras la Justicia. Una introducción al Derecho y al razonamiento jurídico, Ariel, 1993, págs. 182 y ss.
} 
tipo de estudios es la inclusión (como defiende Atienza) o no (como mantiene Wroblewsky y con él la mayoría) de la racionalidad ética dentro de los cometidos de la llamada ciencia de la legislación.

El enfoque minimalista puede, ciertamente, conseguir, al menos, lo que Lon Fuller denomina $^{47}$ «moralidad interna de la ley» evitando adentrarse por aquellos caminos que conducen al naufragio de la norma y, entre los que destaca L. Fuller, el fracaso en darlas a conocer, el abuso de las normas retroactivas, la incomprensibilidad de la norma, la promulgación de normas contradictorias, la norma que exige lo imposible, los continuos cambios en la norma y el fracaso entre el texto de la norma y su administración. Es cierto que la ciencia de la legislación puede ayudar a evitar estos desvaríos. Lo cual no garantiza la justicia de la norma; pero también es cierto que sin el respeto de toda una serie de condicionantes técnicos no es posible realizar aquella.

Pero parecería grave renunciar a preguntarse por la justicia de las normas. Quienes consideramos que el derecho ha de respetar determinados valores y límites, no calificaríamos como buena una ley técnicamente perfecta pero al servicio de fines ilegítimos e injustos. El trabajo del jurista -insiste con toda razón Elías Díaz ${ }^{48}$ - no puede ni debe reducirse a una labor de interpretación lógico-formal ni de aplicación mecánica de las normas sino que ha de entenderlas en su contexto social e histórico y someterlas a una reelaboración crítica. Pues bien, con mucho mayor motivo el «proyectista» de normas y todos los que participan en las distintas fases normativas no pueden desconocer la perspectiva de la legitimidad, eficaz y crítica, de las normas.

Quienes hemos tenido la suerte -y la seguimos teniendo- de trabajar con Elías Díaz sabemos que su concepción totalizadora y crítica del fenómeno jurídico impide concebir una ciencia de la legislación sin una ética porque, como diría Fernando de los Ríos, no cabe una ciencia sin conciencia.

${ }^{47}$ The morality of Law, Yale University Press, New Haven and London, 1963. págs. 33 y ss.

${ }^{48}$ Legalidad y legitimidad en el socialismo democrático, op. cit., pág. 61. 
$\Delta$

DOXA 15-16 (1994) 